\title{
Pathology in Britain in the First Half of the Twentieth Century, with a Glance Forward*
}

\author{
C. H. BROWNING,, M.D., F.C.PATH., F.R.S.
}

Brit. med. F., 1967, 3, 359-362

I appreciate greatly the opportunity to commemorate my friend E. H. Kettle. Not only was he a distinguished pathologist, too early taken from us, but his wide culture, shining humanity, and rich sense of humour inspired deep affection and respect in all who had the good fortune to know him. We were contemporaries and our active lives in pathology began with this century. In Britain it was an exciting period, since only recently had the subject ceased to be a mere servant of the clinicians. The pioneers of the change were the generation immediately our seniors. Thus beginners like Kettle and myself found circumstances that were new. The current roll of our Pathological Society shows that under 3\% were pathologists in 1924, therefore I shall try to picture affairs during the first half of the century, so that you may appreciate how the present state has evolved. Training, practice, teaching, and research will be touched on. If I draw largely on personal experiences, that is because they are the most vivid. But my conditions were not unusual, except perhaps that the men who influenced me were of quite phenomenal calibre. In the light of what I have learned I shall offer some opinions which may be shared but are not borrowed.

\section{Scope and Status of Pathology-How it Became a Career}

Pathologists had come to belong practically to two classes, hospital and academic. A good physician's interest in his patient after death was to find out whether the postmortem findings had been correctly predicted. In a word, the hospital pathologist was his ancillary. This routine verification of wellknown facts was essential for teaching the natural history of disease, but not much to the benefit of future victims. Of course, there were the occasional curiosities. Surgeons, however, thanks to Lister, now dared to inspect deep lesions during life and supply fresh human tissues for examination. Thus, reporting on operation specimens was a considerable duty. A hospital pathologist's appointment, unlike the clinicians', did not promise lucrative private practice, there being small demand. A few university professorships of pathology existed; but the chance of reaching such a position was remote. These academic pathologists in their departments were isolated from patients in hospital, where at that time the obvious problems lay.

In Glasgow Joseph Coats, besides engaging in clinical work, had been pathologist to a large general hospital and teacher of pathology for about 25 years. Finally he became full-time professor, and soon effected a revolution by securing at the Western Infirmary an Institute where teaching and hospital work were carried on jointly. On its inauguration in 1896 he stated:

\footnotetext{
* Based on the Kettle Memorial Lecture given before the College of Pathlogists on 7 February 1967.

$t$ Professor Emeritus of Bacteriology, University of Glasgow.
}

" Our circumstances here are, I think I may say, unique, and I think I may add that they are in a sense ideal. . . . There is thus combined under one roof and under one superintendence both the Infirmary and the University Pathological Departments. . . My pathological friends tell me that such a conjunction of interest is a happy ideal which is nowhere else realized" (see Browning, 1952). Glasgow's example, however, was only tardily followed elsewhere.

Running a combined department was relatively simple at the beginning. Apart from teaching, the chief occupation was with the hospital's morbid anatomy and histology (including blood examinations). Histological methods were similar to today's, but fewer and simpler-present histochemical methods are an example of the change. The preservation of natural colours in naked-eye museum preparations had begun, but the treasures on the shelves were in spirit. I remember concluding that time could be spent better than by visiting there. Chemical pathology was represented chiefly by simple side-room tests. Medical microbiology and parasitology consisted mainly of examining pus for organisms, throat swabs for diphtheria bacilli, sputum and urine for tubercle bacilli, intestinal contents for the typhoid bacillus, dysenteric amoebae, or worms, and blood for malarial parasites or microfilariae. Serology consisted of a micro form of Widal test. Animals were occasionally inoculated for detection of tuberculosis, also for plague which visited Glasgow at that time. Blood cultures were rarely asked for. Research in pathology was generally taken to mean the description of unusual cases; the experimental method was reintroduced to us in 1899 by Coats's successor, Robert Muir, with his investigation on leucocytosis. The most striking later advances have been the wider understanding of chemical pathology, the growth of bacteriology (including immunology and virology) stimulated especially by the war of 1914-18, haematology, and genetics. Increased interest in the living patient and the active development of the experimental approach have been of vital importance. It is scarcely possible to exaggerate the debt of human pathology to the scientific study of protracted model diseases induced in animals. Various names are given to different aspects of this discipline; but since all centre on altered function and structure, they are pathology.

After Coats's innovation there arose the problem of training a body of young pathologists for future needs. Pathology had always attracted keen men; for a few years they acted as junior teachers or hospital pathologists, but then shifted to the clinical side. Earlier still there were the famous physicians and surgeons whose names live in the diseases they identified. One of the later examples was a young surgeon, John Bland-Sutton, who made outstanding contributions on the pathology of the ovaries and Fallopian tubes. When a clinical panjandrum asked where such things were seen, the reply was, "In the public mortuary." A friend who apparently did not relish necropsies had provided this opportunity. The tradition of pathologist- 
physician lingered and "when I was a pathologist" was a familiar expression in London. There were some who could afford to continue their hobby of pathology through possessing private resources-for example, "marrying a nursing-home" or practising vaccine therapy when that became fashionable. Others again were just infatuated with pathology and felt that things must eventually turn out all right; possibly national temperament explained this faith, for at the first meeting of the Pathological Society William Osler remarked that the language of the Society was Scots.

Coats at the opening of his Institute said: “I cannot think of a better way of advancing the scientific position of our school and at the same time conferring great benefits on the community than by some man who is able, conferring a moderate endowment on those who may devote themselves to research." He did not live to see this hope realized, but a Coats memorial scholarship was established in 1899. Growing appreciation of the value of medical research led to foundations and grants by private and public bodies. Personally, I must thank chiefly the Carnegie Trust, the M.R.C., and I.C.I. for support. Various circumstances have increased the demand for pathologists until the number now far exceeds the most sanguine hopes of 1900. Dible's (1957) history of the Pathological Society tells of the devoted men who won recognition for their subject as an independent scientific discipline. A similar magnification of the pathologist's status has occurred in other spheres, and all these changes have accelerated (see Ledingham, 1925). No longer kennelled in the dead-house, the pathologist is now important clinically and in general social esteem. Let us hope that he will not be forced to go abroad in order to find conditions congenial for research, nor be frustrated officially in his effort to serve individual patients.

\section{Training}

As a student starting with a term of morbid histology, both the subject and my teachers, Robert Muir and A. R. Ferguson, greatly attracted me and, being encouraged, I haunted their department. At the time a local epidemic of smallpox broke out and Ferguson was studying the behaviour of the leucocytes and the histopathology of the skin. My interest was aroused and, anxious to do some work, I asked Professor Muir for a subject; he proposed the development of the granular leucocytes in the human foetus. When the results came into print I had graduated in medicine and, the Coats scholarship being open, I applied. There was no other candidate, and after a practical examination I became the first holder; the tenure was a year. Professor Muir asked me to take part in his work on haemolytic sera. He interpreted the scholar's duties in a most enlightened way by arranging that only part of the time was spent on research, thus leaving the rest at disposal for me to become familiar with the round of the Institute. I also attended a postgraduate laboratory course in medical bacteriology. My only "menial" duty was, in the first few months, to wash blood suspensions by turning a hand centrifuge until a small electric one was built. I read widely round the various subjects of the daily work and tutored several students-an admirable exercise for a future instructor.

Gaining a Carnegie fellowship and, on Muir's recommendation, accepted by Ehrlich as a voluntary worker, I went to Frankfurt late in 1905 and stayed till the autumn of 1907. At first I worked on haemolysis under the kindly eye of Hans Sachs; but soon Roehl, engaged on the biological side of trypanosomiasis chemotherapy, left and I replaced him. This was the greatest good luck, because during a year and a half I came into the centre of Ehrlich's chief interest. The GeorgSpeyer-Haus for experimental chemotherapy was soon opened with both chemical and biological departments; so I made contact with the chemists. A landmark of that time was the arrival of Miss R. Gulbransen in the biological department.
Afterwards, in 1916, I was able to invite her with support of the M.R.C. to share in research on the aminoacridine antiseptics; she came at once to Britain from her native Norway to further this work. Thus began a fortunate collaboration, which lasted some 20 years.

The personalities of both Ehrlich and Muir fascinated me. Muir was rather uncommunicative as a rule, from preoccupation mainly, and his intentions had to be divined; on formal occasions, however, he was magnificently clear. Ehrlich, never at rest, talked with telling vivacity and wit, yet nothing was unpremeditated. Both were highly concentrated men and did not relish interruptions. I recall vividly their occasional reactions. The laboratory which Muir used for haemolytic experiments was shared by a budding clinician doing a small bit of bacteriology. No doubt he hailed meetings with an influential figure like the professor as a useful opportunity to ripen acquaintanceship; so he made small talk. This was tolerated for a time, until one day on opening the door Muir saw the man and immediately, raising his arm prophet-wise, said emphatically, "X, I am busy this morning." Once on going to Ehrlich's room I found him arranging matters with a senior member of the institute; concluding, he said that they would continue next forenoon. The other replied that he was sorry, but he had a piano lesson at that time. Ehrlich courteously changed the hour and they parted; then eyeing me sternly he said, "You must have only one wife." I can think of no greater exhilaration for a young pathologist than the period with Ehrlich, though eventually, I fear, one would have burnt up in his fire, just as he consumed himself. With Muir I spent over 25 years; his fine critical mind, unbreakable integrity, generosity in allowing pupils to follow their own bent, and high appreciation of life both mental and material made a lasting imprint (Ehrlich, see Muir 1915-6 ; Browning, 1954, 1955 ; Muir, see Cappell, 1961).

These first four graduate years-including six months as house-physician-were a sort of informal apprenticeship quite free from the burden of impending examinations or other routine. They were the most memorable and valuable part of my scientific education. Nowadays, I fancy, it will be almost impossible to reach a senior position without an extra degree in science ; however, I doubt whether such training is superior to my less formal course. But if the extra degree is necessary meanwhile, I should recommend the bare minimum of written examinations. These may serve in the words of Robbie Burns as the fear of hell that holds the wretch in order; but I am sure that such trials ultimately sap independence of mind. For the beginner, time spent in research, especially jointly with an experienced investigator, is invaluable and enjoyable. It shows how difficulties arise and the ways in which they are tackled. Sound initiative, usually a slowly maturing faculty, is fostered. There is a dilemma-how much to read ? The immense cargo of knowledge piling up everywhere today may eventually hinder advance; repeatedly I have met sharp young people who decided from reading that what can be has been done, so why further effort. It appeals to me as a most enlightened provision of this College that Membership may be gained by published original work. I hope this approach will be freely encouraged.

\section{Practice and Teaching}

I was offered a university assistantship by Professor Muir soon after my return from Frankfurt. Personal selection of staff worked well in his hands to judge by the performance of the long line of his young people. At first I shared the general teaching and hospital work, later becoming responsible successively for bacteriology and clinical pathology. In 1911-12 the professor's official medical staff consisted of three, with several part-time demonstrators for the practical classes. When I was appointed first director of the Bland-Sutton Institute at the Middlesex Hospital duties were similar, except that I secured. 
Ernest Kennaway to undertake chemical pathology. In time the irresolvable uncertainties of histopathology disillusioned me ; it is an essential subordinate, but can be a deceitful master and may lead its devotees into devious courses-for example, fixing all of a specimen where tuberculosis might be suspected.

On returning to Glasgow in 1919 to the new chair of bacteriology, I fortunately was housed in the Pathological Institute. At Muir's suggestion pathology and bacteriology lectures were closely dovetailed. For instance, as soon as the other aspects of pyogenic diseases were dealt with, their bacteriology was taken up. I am convinced that such integration is the best way of dealing with the pathology of infections for medical students. They require a basic understanding of the science without the detail suited to specialists. I quote as the highest compliment words of Sir Robert Muir (1950): “Many teachers of the present day would benefit if they knew both what bacteriology was and how much Browning thought it necessary to teach the ordinary medical student. If they cut their courses accordingly, I think it would be of great importance in the medical curriculum." As to the form of teaching, since knowledge is best acquired through as many sensory paths as possible, specimens and lantern demonstrations accompanied each lecture. However, tutorials and demonstrations should familiarize students with the main points of a subject before they attend formal lectures by a senior teacher; these can then be a perspective with emphasis on outstanding features. Unfortunately the order is usually reversed and one has to talk systematically to an audience both ignorant of the vocabulary and incapable of taking useful notes. Practical courses in pathology should contribute to training in manual dexterity. Medical men require skill in using their hands; and opportunities to acquire this are indispensable. The teaching which was mutually most rewarding took place in small practical classes and discussions with graduates engaged in research. When a junior turned his results into words for publication an important duty was to ensure that he made himself intelligible. I always found lucid, accurate expression on paper difficult ; and few others seem less hampered. I chose knowledgeable young people to read my own MSS. When they queried any point, an acceptable alteration was devised. Obviously, if the reader had difficulty in grasping what was intended, the writer had failed and it was best to try again. Often I have asked the author of an unintelligible jumble, "Tell me what you wish to say," and at once he would give a brief and clear statement. However, I do not suggest composition by direct dictation. It is essential to write a draft, read it, make changes, rearrange words, paragraphs, etc., and then get a typed copy, which will show up further imperfections. I have known half a dozen redrafts to be required.

Examining never gave me satisfaction. Excellence in written papers is certainly no guarantee that a candidate will be good at his profession, but only means that he has a faculty commonly associated with general capacity. I have greater confidence in "practicals" and "vivas," which represent conditions much more akin to situations in real life. However, there are many young people who prefer written tests. This, I fancy, depends much on two factors-one is the elasticity of the inexperienced mind, which can accommodate a whole science for several days and disgorge chunks on demand; the other is shyness, which recoils from a possibly unsympathetic human confrontation. Not all examiners possess the tact of Kettleonce when about to interview a Scottish student, he asked, "Who are you ?" and the answer was "Fine, thank you"; whereupon Kettle paused, looked at his list again and said, "Very good; now what is your name?" If there were sufficient teachers I would accept their opinion that a candidate should pass. In case of an adverse judgement an independent examination would be available as a sort of court of criminal appeal. I entirely agree with a statement of Robert Muir that good performance in examinations serves chiefly to bring to the notice of their seniors students who lack financial backing.

\section{Research}

While in the inanimate world spectacular triumphs of accomplishment abound-for example, in engineering-it is humiliating that we still signally fail to cope with more than a few of the biological derangements which afflict man and other animals. Research, actively pursued, is imperative. A medically trained pathologist who does not feel that adventure in his domain is a large part of the salt of life has surely mistaken his vocation. But the way has been difficult. As we saw, this century found the pathology departments of universities and hospitals mainly separate. Hospital authorities generally viewed research in pathology, particularly of the experimental kind, as at best a luxury. There is now much improvement, but even yet facilities for research could be more accessible ; all who show aptitude (which is not yet measurable by the usual examinations) should possess the opportunities. The idea of separating research sheep from routine goats, with no common field, is frustrating. To be convinced of this one has only to watch the personality of an individual who, in addition to answering the calls of others, is also making progress with an investigation, preferably of his own choice. There is, too, the mass benefit conferred on his fellows. Of course, this implies no criticism of fine research institutions-for example, the Lister, a private organization, or the National Institute. As to "team-work," this can be highly effective only when it is a free association of individuals possessing various mental or physical skills, who jointly face an intricate problem.

Valuable results could be obtained even recently with moderate material outlays apart from the essential element of time. But now expenses grow ever greater; where are the means to be got ? Calls in the name of specified diseases used to be very successful. But benefactors cannot be guaranteed any sure return; the only promises are past successes. Another important consideration is that investigation may be hampered by too precise terms of a gift. Cancer, coronary thrombosis, poliomyelitis are all dreaded and appealing words. But the best prospects of ameliorating such maladies and of general progress in the mastery of disease probably lie in research under less restricted designations-for example, growth, degeneration, viruses. As Ehrlich aptly put it, research is like a voyage in a balloon; one never knows in advance what the scenery will be on landing, but it is essential to be prepared to appreciate its features. It is clear that the number of people able to play Maecenas has of late drastically diminished. Their successors are committees, boards, or trusts, all multiple impersonalities whose judgements will be governed by presumed responsibility to others, compromise, and so on. Collectively they are likely to lack the faculty of making the bold wise decision open to one person disposing of his own. In any case, nobody but the researcher himself should decide what road he will follow, and he must be trusted. That does not mean that his judgements will always be right. Nevertheless, at least a proportion of research should be financed privately. If there are no longer large givers, there might well be many moderate ones responsive to appeals honestly advanced.

How does the investigator get his ideas-probably in various ways, sometimes unknown to himself. Certain minds seize fruitful analogies which are unguessed by most. For Medicine, particularly, a classic instance is Lister's inspiration that the agents of sepsis in wounds, like those of Pasteur's fermentation. and putrefaction, must be micro-organisms. On the whole, however, there is not much explicit information as to why experimenters have acted as they did. In my cxperience, which conforms with general belief, new concrete facts are usually discovered by the scientific exploration of observations made under novel conditions. Such conditions may arise spontaneously or be produced experimentally; they need not be created on the basis of a theory. It must be added, however, that extraneous circumstances often play a large part in determining the impontance attributed to any particular discovery, 


\section{Prospects}

Extension of the field has been phenomenal and yet so many unsolved problems remain that one cannot but be hopeful of further progress. Most encouraging is the knowledge of what Nature unassisted occasionally brings about. It is foolish to guess what will be the next discoveries; there have been too many fatuous prophecies. After all, Penicillium notatum was wafted on to the culture of one who had spent much effort to demonstrate the impossibility of effecting locally what penicillin afterwards accomplished systemically. Again, to promulgate that cancer is an inevitable genetic vice seems a gambler's throw when metastases may develop after 20 years of latency following surgical removal of a primary ; and still more astonishing is spontaneous regression of malignant tumours in man. Pathology is a science and ant dependent on tools provided by chemistry and physics. It is now obvious that physical pathology will be actively fostered like its chemical twin. On one thing, however, I feel sure-so long as we remain human beings we shall never fathom the whole intricacy of disease processes. But we can expect to multiply powers of modifying these processes at decisive points, so as to prevent, compensate for, or even reverse derangements which interfere with healthy functioning.

I would pose several questions with another bearing. Even recently, medical pathologists were competent technicians, free to advance their subject by new methods and observations. Is this to be suppressed by administrative demands or replaced by computers? Again, what about the respective responsibili- ties of those medically qualified and the others who lack this background ? Can the latter be reliable advisers in many problems concerning patients? On medical education in general my only comment is strong approval of the view that a nominally "all-in" qualification is an anachronism. It should be replaced by a primary qualification requiring a less detailed but broader pupillary curriculum, and this would be followed in a proportion of cases by preparation for a special qualification. Further, it is only common sense that a candidate's primary qualification should normally be gained at about age 25 and thereafter he be entitled to earn as well as learn. Means must be found, however, to prevent the cruel waste involved in rejecting candidates at the later stages of primary training.

To end, I recognize that pathology has now reached a diversity and a complexity which prevent more pathologists of my sort from emerging. The conuitions of Membership of the College are clear evidence for this. At the same time I cannot but regret that an existence so varied and enjoyable should become impossible.

\section{REFERENCES}

Browning, C. H. (1952). Fortuna Domus, p. 249. Univ. Glasgow. (1954). Brit. med. F., 1, 664 (1954). Brit. med. F., 1, 664. Cappell, D. F. (1961). F. Path. Bact., 81, 261. Dible, J. H. (1957). Ibid., 73, Suppl. pp. 1-35 Ledingham, J. C. G. (1925). Brit. med. f., 2, 554. Muir, R. (1915-16). f. Path. Bact., 20, 350. Muir, (1950). Lancet, 1, 936.
A conference on recent advances in plasmaprotein disturbances and proteinuria was held at the Royal College of Physicians of London on 7 and 8 July.

Professor Sheila SHerlock (Royal Free Hospital, London) was chairman of the first session, at which Dr. T. Freeman (National Institute for Medical Research, London) outlined the functions of certain plasma proteins. $\mathrm{He}$ pointed out that Laurell electrophoresis had now made possible both the quantitative and qualitative assessment of plasma-protein fractions, and that nearly 50 different types, several of them still unnamed, had been demonstrated, though the functions of most of them were not yet understood. Dr. Freeman divided the plasma proteins of known function into two categories- " suicidal " proteins, which were broken down in performing their task, and biophilic proteins, which were used rspeatedly. Chain reactions employing suicidal proteins might be a safety device resembling a combination lock, the proteins being destroyed because their actions, in some cases at least, were potentially dangerous. Compleme-t and the formation of fibrin from fibrinogen were examples of this.

Though albumin comprised the largest fraction of the plasma proteins and had been studied most, its function was still poorly understood. In the past albumin had been thought of as a reserve pool of amino-acids, but at least two other functions were more likely possibilities. Firstly, albumin provided

\section{[From a Special Correspondent]}

a non-specific transport mechanism for many substances, including bile acids, metals, drugs, and excesses of vitamins and hormones. Secondly, in common with the other plasma proteins, albumin maintained the colloid osmotic pressure of the blood. Nevertheless, high albumin levels were not essential for the latter because patients with the rare condition of analbuminaemia generally remained remarkably well. Dr. Freeman went on to describe the functions of two other plasma proteins which were better understood. The substance transferrin bound iron atoms and carried them to the reticulocytes, and it also appeared to have some antibacterial action. Haptoglobins of several types combined with haemoglobin, and probably acted as scavengers. He thought that it was likely that all plasma proteins had specific functions, and that new techniques would lead to great advances during the next ten years.

\section{Liver Disease}

Discussing the influence of liver disease on plasma-protein levels, Dr. V. M. Ros ENOER (Royal Free Hospital) divided the plasma proteins into two main groups-the immunoglobulins, synthesized extrahepatically, and the remainder, synthesized wholly or mainly in the liver. A high proportion of patients with liver conditions had increased immunoglobulin levels, but these were not disease- specific and therefore had no use in differential diagnosis, neither did their presence imply the existence of an autoimmune process in the liver. Similarly, the fall in blood levels of plasma proteins formed in the liver had been found to bear no direct relation to individual hepatic diseases. Nevertheless, it had been possible to develop methods for the direct study of plasma-protein synthesis rates in the liver by the use of radioactive tracers. Surprisingly, these studies had produced no evidence of a feedback mechanism by which the serum albumin concentration could influence the rate of albumin synthesis.

Dr. Rosenoer concluded by emphasizing the importance of an adequate supply of amino-acids for protein synthesis, and suggested that protein intake should not be unduly restricted in patients with liver disease; nor, on the other hand, was it useful to give excessive quantities of protein. Normal dietary levels were usually best.

Dr. G. Neale (Royal Postgraduate Medical School, London) instanced some diseases associated with hypoproteinaemia, pointing out that low levels of albumin and other plasma proteins were caused either by reduced production (in liver diseases and malnutrition of the kwashiorkor type), by increased catabolism in acute illness, or by direct loss from the body. The last tnok place through the skin after burns, from the kidneys in the nephrotic syndrome, and from the gut in protein-losing enteropathy. Protein loss 